\title{
What makes medical students to say "yes" to e-learning?
}

\author{
Dr. Nalinda Silva MBBS, PhD \\ Lecturer, Department of Physiology, Faculty of Medical Sciences \\ University of Sri Jayewardanepura \\ E-Mail address: yasanga78@yahoo.com
}

\section{Dr. Varuni Tennakoon MBBS, MPhil}

Senior Lecturer, Department of Anatomy, Faculty of Medical sciences

University of Sri Jayewardanepura

E-Mail address: varuni16email@yahoo.com

\author{
Dr. Nadeeja Niranjalie Wijayatunga MBBS \\ Lecturer, Department of Biochemistry, Faculty of Medical sciences \\ University of Sri Jayewardanepura \\ E-Mail address: nadeejawi@yahoo.com
}

Sri Lanka Journal of Bio-Medical Informatics 2013;4(1):7-13

doi: http://dx.doi.org/10.4038/sljbmi.v4i1.5523

\begin{abstract}
Introduction

With exponential expansion of Information Technology, the field of medical education has embraced innovative electronic learning (e-learning) techniques. The objectives of this study were to assess the acceptance of an integrated e-learning activity by first year medical students and to explore the association between the pattern of computer usage and their perception of such an intervention.
\end{abstract}

\section{Methods}

A study was conducted among first year medical students $(n=95)$ using a pre-tested validated self-administered questionnaire following an interactive e-learning activity which integrated the three basic sciences Anatomy, Physiology and Biochemistry.

\section{Results}

Mean $\pm(\mathrm{SD})$ age at first use of a computer was $11.25( \pm 2.9)$ years with a range of 4-20 years. Majority in this group $(96.8 \%)$ were using a computer before the age of 16 years. All those surveyed had access to a computer where a majority $(77.9 \%)$ possessed their own computer. A majority of students $(97.9 \%)$ mentioned that elearning should supplement their lectures. The likelihood of students agreeing that e-learning should supplement their lectures was 2.3 times more in those who started using a computer before the age of 11 years $(95 \% \mathrm{CI}$ $1.001-5.449, p=0.045)$.

\section{Conclusions}

In this group of first year medical students, positive perception towards an integrated e-learning activity was associated with the use of a computer at an early age.

Keywords - e-learning; first year medical students; information technology; computer usage

\section{Introduction}

Information Technology has become a useful tool for managing medical knowledge in patient care as well as in research. With exponential expansion of IT, the field of medical education has also embraced innovative electronic learning (e-learning) techniques ${ }^{(1)}$. Benefits of elearning on the performance of medical students have been demonstrated in Western ${ }^{(2)}$ as well as in Asian countries ${ }^{(3)}$ with the latter group of researchers demonstrating the 
effectiveness of e-learning activity on the results of education of Biochemistry ${ }^{(3)}$; a basic science taught during the first year of medical school.

In Sri Lanka, lack of IT capabilities among first year medical students has been identified as an impediment to introducing e-learning material in the assimilation of knowledge ${ }^{(4-6)}$. Such deficiencies are likely to affect the perception of students on e-learning activities based on basic sciences viz. Anatomy, Physiology and Biochemistry which are taught during the first year of the medical curriculum. A high rate of acceptance for IT based learning/teaching methods has been observed among medical students in Medical Faculties at Colombo ${ }^{(7)}$ and Rajarata $^{(8)}$ universities. However, while Yapa et $\mathrm{al}^{(7)}$ focused on the attitudes of medical students towards a learning management system, Wijayarathne and co-researchers have published on the perception of first year medical students on information and communication technology course that was conducted during the first term of the medical course. Hitherto there is lack of data on student perception on e-learning activities aimed at delivering concepts of basic sciences.

On the other hand, the attitude of medical students towards e-learning is known to be variable with numerous determinants being identified. Computer usage pattern is one such determinant as illustrated by a study carried out at the Medical University of Vienna where the intensity of computer use had the greatest effect on first year medical students' attitudes towards e-learning ${ }^{(9)}$.

In 2007, the Faculty of Medical Sciences, University of Sri Jayewardenepura made a transition into a more student centered, integrated and systems based curriculum where self learning through e-learning material was intended to form an integral part. Incorporation of elearning into the curriculum was based on the high level of acceptance for IT among medical students at Sri Jayewardenepura ${ }^{(6)}$. To facilitate e-learning, an IT component was incoorperated in the orientation conducted during the first five weeks of the medical course, during which the students are introduced the basics of IT and e-learning. In addition, dedicated time is allocated in the schedule where students are required to visit the Resource Center and utilise the available e-learning material.

In 2013, using such a dedicated time allocation, we introduced an interactive e- learning activity based on the thyroid gland to a batch of first year medical students during their third term. Since integration constitute a cornerstone of the new curriculum, learning/teaching elements from the three basic sciences were duly integrated in this e-leaning activity. We hypothesised that the perception and acceptance of such an interactive session might be different from that reported by Yapa et $\mathrm{al}^{(7)}$ and Wijayarathne et $\mathrm{al}^{(8)}$ since the particular batch of students have had previous exposure to IT and e-learning.

The objectives of this study were to assess the acceptance of an integrated e-learning activity by first year medical students and to explore the association between the pattern of computer usage and their perception of such intervention.

\section{Methods}

This study was conducted among first year medical students $(n=150)$ during their third term in the Faculty of Medical Sciences, University of Sri Jayewardenepura. The interactive elearning activity was designed by the three authors using Microsoft Power Point software which integrated the three basic sciences namely Anatomy, Physiology and Biochemistry. To synchronise with the endocrine and metabolism module that was conducted during this 
period, the thyroid gland was selected as the common theme. The interactive e-learning activity included fill in the blanks, selection of the best response and naming of anatomical structures. The students were provided feedback by giving the correct answer and a brief explanation where appropriate. All the students who were present for the IT session $(n=150)$ were given adequate time to experience the interactive session.

Following the completion of the endocrine and metabolism module, the same group of students was approached and after obtaining verbal consent a pre-tested validated self administered questionnaire was given to the participants. The questionnaire contained specific questions (for example, "computer or e-learning should be made available to supplement lectures") where the student had to select one of the responses from agree, undecided, disagree or strongly disagree. In addition the pattern of computer usage was assessed with the students being instructed to select the frequency of usage according to a scale that ranged from never to daily. For statistical analysis the responses to specific questions on perception were dichotomised with the amalgamation of undecided, disagree or strongly disagree into a single category of "disagree". The means were compared with t-test and the Spearman correlation which was used to assess the association between continuous variables. Mean age at first use of a computer was used to dichotomise the population. For dichotomous variables, Chi square test was performed to compute odds ratios together with $95 \%$ confidence intervals. A $p$-value less the 0.05 was considered as significant. Ethical clearance for this study was granted by the Ethics Review Committee of the Faculty of Medical Sciences, University of Sri Jayewardenepura.

\section{Results}

A total of 95 students completed the questionnaire that corresponded to a response rate of $63 \%$. Mean $\pm(\mathrm{SD})$ age at first use of a computer was $11.25( \pm 2.9)$ years with a range of 4 to 20 years. Majority in this group of medical students $(96.8 \%)$ had used a computer before the age of 16 years (Table 1$)$.

\begin{tabular}{|l|l|}
\hline Age category & $\mathbf{n}(\boldsymbol{\%})$ \\
\hline Below 10 years & $13(13.7)$ \\
\hline Between 10 and 16 years & $79(83.1)$ \\
\hline Above 16 years & $3(3.2)$ \\
\hline
\end{tabular}

Table 1. Distribution of students according to the age at first use of a computer

All those surveyed had access to a computer. The majority (77.9\%) owned a computer while the rest had either a computer shared by family members $(15.8 \%)$ or access to a public computer (6.3\%). Only three students $(3.2 \%)$ had no access to internet. Prominent use of social media was evident among those surveyed as $37.9 \%$ used the computer to access Face Book on a daily basis (Figure 1). Close to half of the study population (46.3\%) searched the web for educational purposes with $25.3 \%$ reporting the use of a computer on a daily basis for that purpose (Figure 1). 
Responses to specific questions regarding e-learning activities or the interactive activity (Table 2) served as proxy indicators of the positive perception of students towards e-learning. Satisfaction with the interactive session positively correlated with the preference for future computer based activities (Spearman's rho $=0.776, \mathrm{p}<0.001$ )

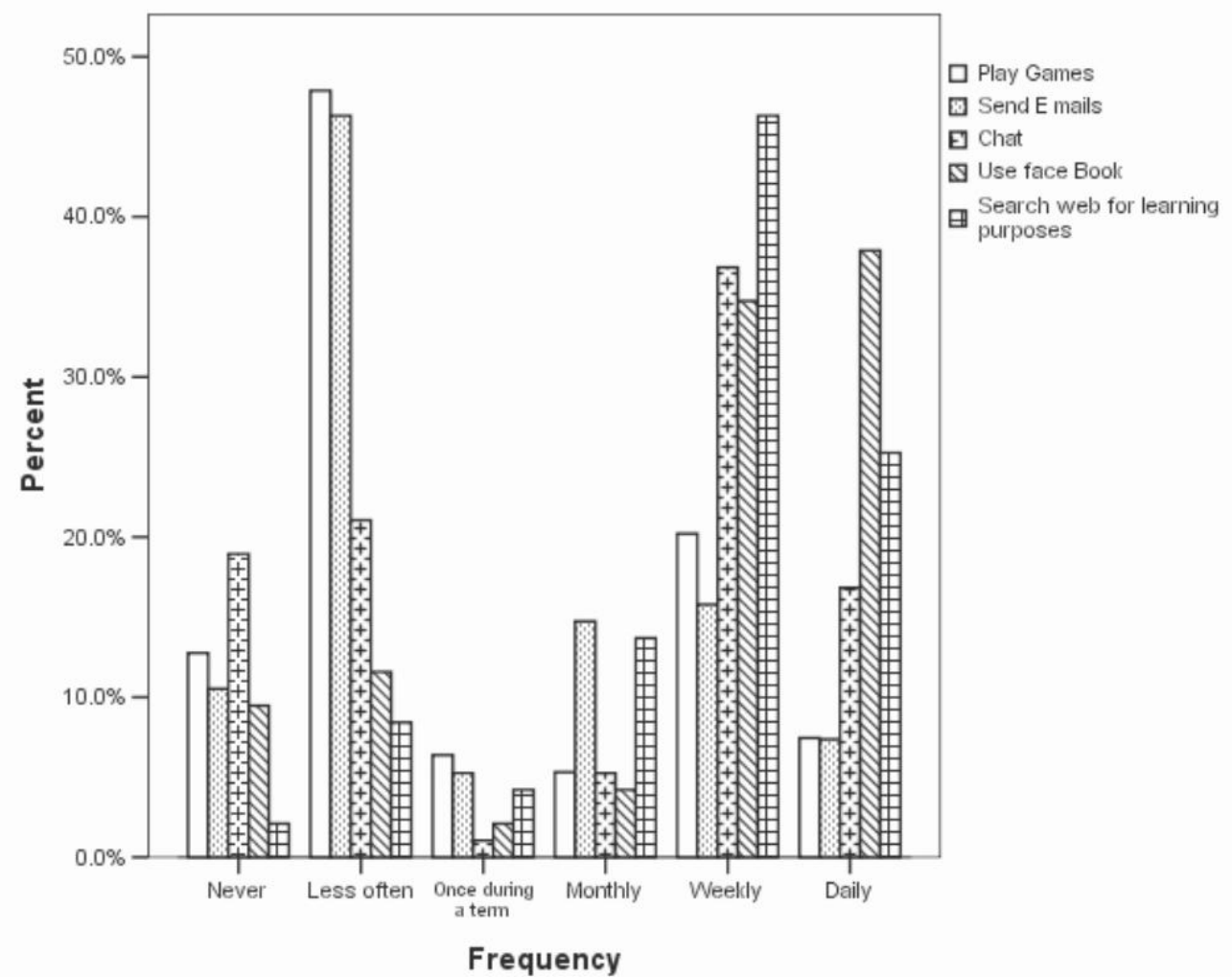

Figure 1. Frequency of computer usage among the participant medical students for educational and/or non educational purposes

\begin{tabular}{|l|l|l|}
\hline & Agreeing \% & Disagreeing \% \\
\hline E-learning should supplement lectures & 97.9 & 2.1 \\
\hline E- learning in medical teaching is unnecessary & 3.2 & 96.8 \\
\hline Interactive activity was interesting & 96.8 & 3.2 \\
\hline Interactive activity reinforced the knowledge & 98.8 & 1.1 \\
\hline Interactive activity fostered critical thinking & 93.7 & 6.3 \\
\hline $\begin{array}{l}\text { Interactive activity developed the interest in the } \\
\text { subject/s }\end{array}$ & 92.6 & 7.4 \\
\hline Satisfied with the learning experience & 97.9 & 2.1 \\
\hline Prefer to have more interactive activities & 97.9 & 2.1 \\
\hline
\end{tabular}

Table 2. Percentages of participants agreeing or disagreeing to specific questions 
The likelihood of students agreeing that e-learning should supplement their lectures was 2.3 times more in those who started using a computer before the age of 11 years (95\% CI 1.001 5.449, $\mathrm{p}=0.045)$.

\section{Discussion}

In this study, a high degree of acceptance for an interactive e-learning session was evident among medical students while the level of satisfaction positively correlated with the preference for future IT based learning sessions. Furthermore, using a computer at an early age was associated with positive perception towards e-learning.

In respect to the rate of acceptance of e-learning among medical students, results of this study are in agreement with the previous reports from Sri Lanka and elsewhere. While Wijayarathne et al. report on an acceptance rate of $91.3 \%$ among a group of Sri Lankan first year medical students ${ }^{(8)}$, Link and Marz report that a great majority of first year medical students acknowledge the advantages of interactive IT based learning material ${ }^{(9)}$. Yapa and co-investigators found that $94.7 \%$ of those surveyed preferring supplementary learning material to be incorporated in the Moodle platform although their study did not exclusively consider first year medical students ${ }^{(7)}$.

Taken together it is plausible to deduce that in general the rate of acceptance for e-learning activities among first year medical students is considerably high irrespective of geographical locations. Furthermore, in the survey conducted by Fernado et al. $78 \%$ of students agreed that computer skills are essential for doctors and $84 \%$ thought that professional life could be improved by using $\mathrm{IT}^{(6)}$.

Varghese et al. who focused on an e-learning activity based on Biochemistry, report that the extent to which students understood the subject and their ability to answer questions in assessments had improved as a result of using IT resources ${ }^{(3)}$. Thus the dividends from an elearning activity may also contribute towards the positive perception of students. This is reflected in the present study where the level of satisfaction positively correlated with the preference for future IT based learning activities although the level of satisfaction remains highly subjective. However, the positive perception of first year students towards e-learning could be exploited in the introduction of future IT based learning/teaching sessions.

In this study the apparent positive perception towards e-learning was associated with the early use of a computer. It is noteworthy that some students in the present study have become conversant with computers from an age as early as four. Although not inquired in our questionnaire, it is probable that this batch of students have studied Information and Communication Technology (ICT) in their ordinary level classes. In 2006, as part of a major drive to boost IT literacy, ICT was introduced by the Ministry of Education to school curricula (NIE, 2006). As a cumulative result of the aforementioned factors students may have been inclined towards e-learning that has been reflected in the present study.

Nonetheless, the mere possession of either a computer or IT capabilities is unlikely to make the students benefit from e-learning. Many of the students in the present study group frequently used a computer for non educational activities such as browsing social media. Katulanda et al too observed that medical students used computers most frequently to play games $^{(5)}$. Researchers have attributed the low usage of computers for educational purposes to 
the lack of suitable and interesting e-learning activities ${ }^{(8)}$. The possibility of introducing elearning activities as distant learning modules to medical students should be entertained considering that almost all the students in the present study had internet access. In fact a few students who participated in the present study had commented that e-learning activities should be made available via the Faculty website to be accessed from their personal computer.

In conclusion, in this group of first year medical students the positive perception towards an integrated e-learning activity was associated with an early use of a computer. Furthermore, findings of this study are indicative of the fact that present day first year medical students are IT savvy and as such introducing e-learning to the medical curricula is feasible.

\section{References}

1. Khogali SEO, Davies DA, Donnan PT, Gray A, Harden RM. et al. Integration of elearning resources into a medical school curriculum. Medical Teacher 2011; 33: 311-18. doi: http://dx.doi.org/10.3109/0142159X.2011.540270

2. Boye S, Moen T, Vik T. An e-learning course in medical immunology: Does it improve learning outcome? Medical Teacher 2012; 34: e649-e653.

doi: http://dx.doi.org/10.3109/0142159X.2012.675456

3. Varghese J, Faith M, Jacob M. Impact of e-resources on learning in biochemistry: firstyear medical students' perceptions. BMC Medical Education 2012; 12(21)

4. Kommalage M, Gunawardena S. Feasibility of introducing information technology-based activities into medical curricula in developing countries. Medical Education 2008; 42(1): 113.

doi: http://dx.doi.org/10.1111/j.1365-2923.2007.02906.x

5. Katulanda P, Kudalugoda Arachchi J, Cassim MRN, Fernando SSD, Sheriff MHR.A. Survey of computer usage and awareness among medical students (1999) Proceedings of 1st academic session of The Health Informatics Society of Sri Lanka (HISSL).

6. Fernando S, Marasinghe RB, Jiffry MTM. Survey of Computer usage among medical students (1999) Proceedings of 1st academic session of The Health Informatics Society of Sri Lanka (HISSL).

7. Yapa YMMM, Dilan MMNS, Karunaratne WCD, Widisinghe CC, Hewapathirana R, et al. Computer Literacy and Attitudes towards eLearning among Sri Lankan Medical Students. Sri Lanka Journal of Bio-Medical Informatics 2012; 3(3): 82-96.

8. Wijayarathne HK, Walpola VR, Mahamithawa AMP, Bandara DGDPDS. Newly entered medical students' views on an Information Communication Technology course. Sri Lanka Journal of Bio-Medical Informatics 2012; 3(3): 97-100.

9. Link TM and Marz R. Computer literacy and attitudes towards e-learning among first year medical students. BMC Medical Education 2006; 6(34): 1-8.

10. Karamizadeh, Zarifsanayei N, Faghihi AA, Mohammadi H, Habibi M. The Study of 
Effectiveness of Blended Learning Approach for Medical Training Courses. Iranian Red Crescent Medical Journal 2012; 14(1): 41-4. 